\title{
ANÁLISE DE USABILIDADE DO APLICATIVO DE COMPRAS PARA DISPOSITIVO MÓVEL "ZOOM"
}

\author{
ARAÚJO, Maiana Cunha (1); \\ ASSIS, Ana Tereza Santos (2); \\ PEREIRA, William (3); \\ PESSOA, Clarissa (4); \\ SOARES, Marcelo Marcio (5) \\ (1) UFPE, Mestrado em Design \\ e-mail: maianacunha.arq@gmail.com \\ (2) UFPE, Especialização em Ergonomia \\ e-mail: tereza.arquitetura@gmail.com \\ (3) UFPE, Aluno de Graduação em Design \\ e-mail: williampereira685@gmail.com \\ (4) UFPE, Aluna de Graduação em Design \\ email: clarissa.pessoa.luna@gmail.com
}

(5) UFPE, PhD em Ergonomia

email: marcelo2@nlink.com.br

\begin{abstract}
RESUMO
Esta pesquisa foi desenvolvida com a finalidade de avaliar, sob a ótica da ergonomia e da usabilidade, o aplicativo de compras para dispositivos móveis "Zoom", através da análise da interação do usuário com a interface. Como base teórica para a análise, a equipe escolheu os princípios de usabilidade de Jordan (1998) e as heurísticas de Nielsen (1993). Esta avaliação foi feita com o objetivo de identificar como se dá esta interação, observar as heurísticas empiricamente e identificar possíveis fragilidades no aplicativo para propor soluções.
\end{abstract}

Palavras-chave: Ergonomia, Usabilidade, Avaliação, Software, Aplicativo

\begin{abstract}
This research was conducted in order to evaluate, from the perspective of ergonomics and usability, the shopping application for mobile devices "Zoom" through the analysis of the user interaction with the interface. As a theoretical basis for the analysis, the team chose the Jordan's principles of usability (1998) and the heuristics from Nielsen (1993). This assessment was made in order to identify how is this interaction, observe empirically heuristics and identify possible weaknesses in the application to propose solutions.
\end{abstract}




\section{INTRODUÇÃO}

O aplicativo zoom é um serviço online gratuito que permite ao usuário consultar e comparar preços de produtos, dos mais variados setores, entre marcas e lojas nacionais. Seu principal diferencial com relação a outros aplicativos de busca e compra online é a opção de acessar gráficos com o histórico de valores máximos e mínimos alcançados pelo produto em um dado período de tempo. Assim, o usuário pode avaliar se o mesmo está com um bom preço no momento ou se o produto já esteve mais barato anteriormente.

Além de poder analisar preços a partir das buscas e comparações, o aplicativo permite que o usuário salve produtos pelos quais apresentou algum interesse e crie alertas baseados no histórico de preços. Ainda é possível acessar descrições mais especificas do item, avaliações de outros clientes e opinião de especialistas sobre as qualidades e vantagens técnicas. Na hora de realizar a busca, além das categorias preestabelecidas como: smartphone, TV, notebook, livros, CDs\&DVDs, etc, o usuário pode selecionar filtros para uma busca mais específica, ou se por acaso estiver em uma loja, pode utilizar o código de barras do produto para realizar a busca por preços em outros estabelecimentos, ou para buscar outras opções de modelo e marca.

Apesar de ser um aplicativo relativamente recente, o "Zoom" vem adquirindo cada vez mais popularidade em meio a fortes concorrentes, a exemplo do site Buscapé e Submarino. $O$ Zoom é mais uma solução para os usuários interessados em pesquisar e comprar produtos online e por isso foi selecionado para ser avaliado segundo princípios de usabilidade.

\section{A QUESTÃO DA USABILIDADE}

As ações humanas são motivadas por necessidades que representam a busca por algo que na maioria dos casos se alcança através do uso de objetos/sistemas, e a ergonomia e a usabilidade trabalham a questão da interação do usuário com os mesmos, visando sua melhor adequação. lida (2005) define ergonomia como a adaptação do trabalho ao homem, trabalho neste contexto pode ser entendido como qualquer atividade exercida pelo ser humano.

Facilitar o uso de um produto/sistema contribui de forma significativa para atender a satisfação das necessidades do usuário, então a usabilidade surge com um conceito que vem oferecer uma melhor qualidade nesta interação, agindo em conformidade com os princípios ergonômicos. De acordo com a Norma ISO 9241-11, usabilidade é a medida na qual um produto pode ser usado por usuários específicos para alcançar objetivos específicos com eficácia, eficiência e satisfação em um contexto específico de uso.

Para a presente análise, serão levadas em consideração as funções de busca por produtos, comparação de preços e criação de alertas, assim como a forma como essas funções são apresentadas ao usuário, através de um estudo aprofundado da relação usuário-interaçãointerface. Através das três principais métricas de avaliação, eficácia, eficiência e satisfação do usuário, foram selecionados alguns componentes da usabilidade para serem considerados e adquirir resultados quantitativos e qualitativos, como intuitividade, facilidade de aprendizagem, adequação da tarefa, potencial do sistema, etc, e assim apontar possíveis deficiências na usabilidade do aplicativo e como melhorá-las (JORDAN, 1998; NIELSEN, 1993). 


\section{PROCEDIMENTOS DE PESQUISA}

Com base no arcabouço teórico relativo à usabilidade, a pesquisa se deu em duas etapas. A primeira foi a avaliação dos especialistas, no caso, os autores deste artigo. Princípios e heurísticas de usabilidade, referem-se à análise de componentes que determinam as boas ou más práticas do design de um dado produto, advindos de um método chamado de análise heurística, proposto por Jakob Nielsen em 1993. Este tipo de análise, não empírica, é realizada por especialistas e serve para dois propósitos: facilitar a escolha entre diferentes alternativas de design durante a criação e permitir encontrar e justificar problemas durante a avaliação de um produto/software. Também foi feita uma análise dos principais concorrentes, e com isto foi gerada uma matriz de especificação, onde os aplicativos foram analisados comparativamente.

A segunda etapa foi uma avaliação feita por usuários que se enquadraram no recorte que foi considerado como público alvo. Com relação ao aplicativo Zoom, por ser um tipo de produto já existente no mercado, foi analisado o perfil de usuário que utiliza sistemas similares, como o Buscapé e o Submarino. Este usuário é o consumidor comum que utiliza smartphone, com faixa etária entre 18 e 50 anos, que é familiarizado com as plataformas Android ou IOS (as duas foram escolhidas por serem as mais utilizadas por usuários de smartphones). Nesta pesquisa, cujo intuito foi ter uma amostra ilustrativa, foram entrevistados 13 usuários, e portanto, para um resultado mais definitivo, recomenda-se uma investigação com uma amostra mais significativa.

Nesta avaliação foi solicitado que os entrevistados buscassem um determinado produto (foi oferecido a eles a caixa do produto, de modo que poderiam buscar pelo nome ou pelo código de barras), salvassem aquele produto como favorito e em seguida deveriam criar um alerta de preço para aquele produto. Essas operações foram selecionadas porque foram consideradas diferenciais deste aplicativo e, portanto são o principal alvo de análise nesta pesquisa. Em seguida os entrevistados responderam um questionário referente às operações realizadas, para que a equipe pudesse compreender como foi a percepção e as dificuldades do grupo.

\section{ANÁLISE DO APLICATIVO}

\subsection{Avaliação dos Especialistas}

A avaliação inicial feita pela equipe gerou as seguintes considerações:

- O sistema mantém o usuário informado sobre o que ele está fazendo. O feedback não é demorado e é objetivo. Ex: Quando o usuário se interessa por um determinado produto, ele deve pressionar o ícone do coração, que o incluirá na categoria "Seus produtos". Ao ser pressionado, ele tem a sua funcionalidade ativada e isso é refletido visualmente através da mudança da cor branca para a vermelha. Logo após, uma caixa informativa com os dizeres "Produto salvo" aparece. Se o ícone for pressionado novamente pelo usuário, a funcionalidade associada a ele é desativada e este volta à sua cor inicial. Uma caixa informativa aparece notificando que o produto foi excluído;

- Para se criar um alerta, é seguido a mesma lógica. Mas com a diferença que após o ícone do alerta ser pressionado, uma tela contendo um gráfico aparece. Esse gráfico representa a variação de preço do produto num determinado recorte de tempo, e com base nesse gráfico o usuário pode definir o preço pelo qual ele está disposto a pagar pelo produto e quando esse preço for atingido ele será notificado;

- O app é bem intuitivo e é fácil desfazer algumas ações. Caso o usuário salve um produto sem querer, ele pode desfazer a ação simplesmente clicando de novo no ícone do coração. O que facilita a vida do usuário, que teria que ir em "Seus 
produtos" e excluir o produto que foi escolhido erroneamente;

- Há um problema de consistência na versão do aplicativo para Android. Quando o usuário vai excluir um produto do "Seus produtos" ou "Seus alertas", deve pressionar "Excluir". Depois aparece duas opções: "Ok" e um "X" dentro de um círculo vermelho. Se o usuário pressionar o "Ok", ele volta para a tela anterior, mas não exclui o produto. O produto só é excluído, se ele pressionar o "X". O problema é que o "Ok" deveria excluir, já que é uma afirmação e o "X" deveria cancelar a ação;

- O usuário não pode organizar a lista de "Seus produtos" e "Seus alertas" por preço ou por outro critério que deseje. A ordem dos produtos não pode ser alterada e os primeiros produtos são aqueles que foram acrescentados recentemente;

- O app não permite que o usuário faça avaliações dos produtos, apenas visualizar as avaliações já feitas. Apenas o site permite ao usuário fazer avaliações.

Tabela 1 - Problemas em relação à usabilidade.

\begin{tabular}{|c|c|c|}
\hline Problema & $\begin{array}{l}\text { Heurística de } \\
\text { usabilidade } \\
\text { relacionada }\end{array}$ & Recomendação \\
\hline $\begin{array}{l}\text { Na versão para Android, há } \\
\text { um problema na exclusão do } \\
\text { produto na lista do "Seus } \\
\text { produtos" e "Seus alertas". A } \\
\text { função "Ok" deveria } \\
\text { confirmar a exclusão, } \\
\text { enquanto o botão com "X" } \\
\text { deveria cancelar a ação. } \\
\text { Porém, ocorre o inverso. }\end{array}$ & Consistência & $\begin{array}{l}\text { A função "Ok" deve excluir o produto } \\
\text { da lista, ou seja, confirmar a ação de } \\
\text { "Excluir". Enquanto o "X" deveria } \\
\text { cancelar a exclusão. }\end{array}$ \\
\hline $\begin{array}{l}\text { Os produtos nas listas "Seus } \\
\text { produtos" e "Seus alertas" } \\
\text { não podem ter sua ordem } \\
\text { alterada pelo usuário. }\end{array}$ & $\begin{array}{l}\text { Flexibilidade e } \\
\text { eficiência de } \\
\text { uso }\end{array}$ & $\begin{array}{l}\text { Implementação de uma função que } \\
\text { permitisse que o usuário moldasse a } \\
\text { ordem dos produtos de acordo com o } \\
\text { preço, tipo de produto ou qualquer } \\
\text { outro critério que ele queira usar. O } \\
\text { usuário deve ter liberdade de } \\
\text { personalizar determinadas funções } \\
\text { do sistema. }\end{array}$ \\
\hline $\begin{array}{l}\text { O usuário não pode avaliar } \\
\text { produtos através do } \\
\text { aplicativo, apenas pelo site. }\end{array}$ & $\begin{array}{lr}\text { Liberdade } & \mathrm{e} \\
\text { controle } & \text { do } \\
\text { usuário } & \end{array}$ & $\begin{array}{l}\text { Implementação de uma função na } \\
\text { qual o usuário possa avaliar os } \\
\text { produtos pelo aplicativo. Facilita o } \\
\text { feedback do usuário em relação ao } \\
\text { produto. }\end{array}$ \\
\hline
\end{tabular}

Fonte - Elaborada pelos autores com base na pesquisa realizada.

Em seguida foi feita a avaliação de acordo com as heurísticas de Nielsen, estruturada na tabela abaixo: 
Tabela 2 - Avaliação baseada nas heurísticas de Nielsen.

\begin{tabular}{|c|c|c|}
\hline Heurística & Aplicação & Justificativa \\
\hline Coerência & Atende & $\begin{array}{l}\text { Informa o usuário sobre as tarefas realizadas } \\
\text { através de feedback visual. Ex: Ao salvar o produto } \\
\text { através do ícone ( )o mesmo dá um feedback de } \\
\text { que o produto foi salvo através da mensagem } \\
\text { escrita - "salvo em seus produtos" e também através } \\
\text { da mudança de cor do ícone que passa a ficar } \\
\text { preenchido com a cor vermelha ( }) \text {. }\end{array}$ \\
\hline Compatibilidade & Não atende & $\begin{array}{l}\text { O aplicativo deixa a desejar com o ícone de } \\
\text { escaneamento de código de barras, pois não é fácil } \\
\text { por parte de um usuário comum a abstração do } \\
\text { significado do mesmo, desta forma o ícone está } \\
\text { irreconhecível e não representa o que ele se dispõe } \\
\text { a realizar. }\end{array}$ \\
\hline $\begin{array}{l}\text { Controle do } \\
\text { usuário }\end{array}$ & Atende & $\begin{array}{l}\text { Ações indesejadas são facilmente desfeitas e em } \\
\text { caso de o usuário ficar confuso há sempre a } \\
\text { possibilidade de entrar em um menu principal que se } \\
\text { encontra no canto superior esquerdo da tela. }\end{array}$ \\
\hline Consistência & Atende & $\begin{array}{l}\text { O aplicativo possui coerência, visto que tarefas } \\
\text { similares podem ser realizadas através de caminhos } \\
\text { similares. É o caso das tarefas de salvar o produto e } \\
\text { criar o alerta de preço que podem ser realizadas } \\
\text { através dos ícones que ficam na lateral direita da } \\
\text { foto do produto. }\end{array}$ \\
\hline $\begin{array}{l}\text { Prevenção de } \\
\text { erros }\end{array}$ & - & Não se aplica. \\
\hline Reconhecimento & Atende & $\begin{array}{l}\text { Não foram observados problemas relacionados a } \\
\text { esta heurística, não há sobrecarga de nenhuma } \\
\text { habilidade do usuário. }\end{array}$ \\
\hline $\begin{array}{lr}\begin{array}{l}\text { Flexibilidade } \\
\text { eficiência }\end{array} & \text { de } \\
\text { utilização } & \end{array}$ & - & Não se aplica. \\
\hline $\begin{array}{l}\text { Estética e design } \\
\text { minimalista }\end{array}$ & Atende & $\begin{array}{l}\text { O aplicativo possui clareza visual, visto que é } \\
\text { possível compreender as informações fornecidas de } \\
\text { maneira clara e fácil, sem a possibilidade de } \\
\text { dúvidas. }\end{array}$ \\
\hline $\begin{array}{l}\text { Reconhecimento, } \\
\text { diagnóstico e } \\
\text { solução de erros }\end{array}$ & - & $\begin{array}{l}\text { Não foram identificadas mensagens de erro durante } \\
\text { a avaliação das funções do aplicativo. }\end{array}$ \\
\hline $\begin{array}{l}\text { Ajuda } \\
\text { documentação }\end{array}$ & Atende & $\begin{array}{l}\text { As informações mais importantes são facilmente } \\
\text { acessadas pelo usuário através dos ícones que } \\
\text { representam os produtos mais buscados na tela }\end{array}$ \\
\hline
\end{tabular}




\begin{tabular}{|l|l|l|}
\hline & $\begin{array}{l}\text { inicial de busca do produto e através dos ícones, } \\
\text { sempre à mostra, de salvar o produto e criar alerta } \\
\text { de preço. }\end{array}$ \\
\hline
\end{tabular}

Fonte - Elaborada pelos autores com base na pesquisa realizada.

Além das heurísticas avaliadas, foi identificado pela equipe que o aplicativo apresenta transferência adequada de tecnologia, pois utiliza o leitor de códigos de barras que foi criado para outro contexto para aumentar a usabilidade do produto.

\subsection{Matriz de Especificação com Análise da Concorrência}

Após a análise de cada concorrente por parte da equipe, formulou-se uma matriz de especificação, comparando os concorrentes com o aplicativo zoom. Abaixo estão listadas as métricas utilizadas na avaliação:

- Funções disponíveis: funções oferecidas pelo aplicativo, sua relevância mediante as necessidades do usuário e eficiência;

- Interação do usuário: como o usuário interage com o aplicativo, como é a relação de troca de informações e como é a comunicação entre usuário e sistema;

- Interface Gráfica: Linguagem visual apresentada pelo aplicativo;

- Linguagem verbal: Linguagem escrita apresentada pelo aplicativo;

- Facilidade de uso: Nível de dificuldade na aprendizagem que o usuário enfrenta ao utilizar o aplicativo.

Cada concorrente foi avaliado nas métricas especificadas com valores variantes de 1 a 10 . Onde 10 representa o melhor desempenho, e 1, o pior.

Tabela 3 - Matriz de especificações.

\begin{tabular}{|l|c|c|c|c|c|}
\hline & Buscapé & Submarino & Bondfaro & JáCotei & Zoom \\
\hline $\begin{array}{l}\text { Funções } \\
\text { disponíveis }\end{array}$ & 7 & 8 & 7 & 7 & 9 \\
\hline $\begin{array}{l}\text { Interação } \\
\text { do usuário }\end{array}$ & 5 & 6 & 6 & 5 & 6 \\
\hline $\begin{array}{l}\text { Interface } \\
\text { gráfica }\end{array}$ & 6 & 5 & 9 & 4 & 8 \\
\hline $\begin{array}{l}\text { Linguagem } \\
\text { verbal }\end{array}$ & 10 & 7 & 10 & 7 & 10 \\
\hline Intuitividade & 7 & 8 & 8 & 6 & 8 \\
\hline
\end{tabular}

Fonte - Elaborada pelos autores com base na pesquisa realizada. 


\section{AVALIAÇÃO COM O USUÁRIO}

Para verificar os aspectos positivos e negativos do uso de um determinado artefato material ou digital em seu contexto real, é necessário testar com os usuários. Estes usuários, quando forem participar de um teste de usabilidade, devem pertencer ao público-alvo pretendido pelos criadores e desenvolvedores do artefato. Na maioria dos casos, para que um usuário se encaixe em um determinado público-alvo, não deve ter apenas a mesma faixa etária e/ou classe social, mas sim os mesmos hábitos de consumo e conhecimento tecnológico (CYBIS, BETIOL, FAUST, 2007). O público-alvo de aplicativos como o Zoom é um exemplo disso.

Com relação ao objetivo, esses testes de usabilidade do Zoom buscam verificar a facilidade de compreensão e interação dos usuários com o aplicativo. Os testes compreenderam a execução de tarefas típicas pelos usuários, a observação dessa interação e, posteriormente, pergunta dirigidas a eles sobre sua experiência no uso do aplicativo. Esta etapa da pesquisa foi dividida em 3 partes, a primeira foca em traçar o perfil dos usuários entrevistados, a segunda aborda a experiência do usuário com smartphones e serviços de compras online e a terceira focou no uso do aplicativo em estudo, o Zoom.

\subsection{Perfil do Usuário}

O critério de inclusão adotado pela equipe para a seleção dos entrevistados focou principalmente em indivíduos que possuem smartphones e fazem compras online através do mesmo. Nossa amostra resultou por compreender indivíduos com idades entre 18 e 55 anos, o que mostra o potencial de abrangência do aplicativo Zoom.

Ainda tratando do perfil dos usuários, foi observada uma certa equivalência entre os públicos feminino e masculino, Também foi observado o grau de escolaridade dos entrevistados, e observou-se um predomínio de usuários com nível superior completo.

No entanto, a equipe ressalta que só uma amostra mais abrangente poderia definir com precisão se há algum predomínio de determinado gênero ou grau de escolaridade no uso de serviços de compras online e comparação de preços, assim como as demais informações apresentadas nesta etapa.

\subsection{Experiência do usuário}

Todos os entrevistados são usuários de smartphones a mais de um ano, o que configura um grau de experiência elevado com as respectivas plataformas, e esta familiaridade foi considerada fundamental pela equipe para a consideração dos dados referentes à usabilidade, pois demonstra que as possíveis dificuldades encontradas realmente têm relação com o uso da plataforma de compras.

Seguindo a lógica anteriormente mencionada, a etapa seguinte estudou a relação dos usuários com plataformas de compras online e aplicativos de compras em smartphones. Foi observado que mais de $83 \%$ dos entrevistados que utilizam a plataforma Android e mais de $85 \%$ dos usuários do IOS utilizam serviços de compras e comparação de preços online. Também foi observado que somente metade dos usuários do sistema Android utilizam aplicativos semelhantes ao Zoom em seus celulares, enquanto que mais de $85 \%$ dos usuários do IOS possuem e utilizam esses aplicativos.

\subsection{Uso do aplicativo}

A terceira parte da pesquisa focou especificamente na plataforma e na sua usabilidade. A primeira pergunta focou no cumprimento das tarefas propostas, e de todos os usuários entrevistados (mesmo os que encontraram alguma dificuldade) conseguiram cumprir as 
tarefas propostas, exceto um usuário do sistema IOS, que não conseguiu executar a tarefa de retirar o produto da categoria de "produtos salvos".

Os ícones utilizados no programa para a realização das tarefas foram avaliados quanto à sua compreensão, e observou-se que os usuários só tiveram dificuldade em identificar a função do código de barras do menu principal, relatando que acharam que o desenho era somente ilustrativo, e que não havia nenhuma função relacionada a ele. Vale destacar que ao acessar o ícone do código de barras é possível fazer a leitura de um código de um determinado produto, e fazer uma busca mais rápida e específica.

Acredita-se que a dificuldade encontrada pelos usuários do sistema IOS para a identificação do código de barras no menu principal deve-se ao baixo contraste do ícone. No IOS o desenho é cinza sobre fundo branco, enquanto que no Android o desenho tem a cor roxa escura sobre fundo branco.

\subsection{Avaliação geral}

A maioria dos usuários do sistema Android considerou fácil utilizar o aplicativo, enquanto que utilizadores do IOS consideraram muito fácil. Acredita-se que este resultado se deve à consistência dos padrões de aplicativos desenvolvidos para a segunda plataforma mencionada, fazendo com que seus aplicativos possuam um funcionamento similar, o que pode ter facilitado o uso.

Os dois últimos itens da etapa de avaliação geral tratam da eficácia da realização da tarefa e da legibilidade e compreensão das informações fornecidas. Nas duas categorias, mais de $85 \%$ dos usuários do sistema IOS consideram o uso eficaz, e aprovam a legibilidade e compreensão das informações. Essa proporção se torna menos incisiva nos usuários do outro sistema em estudo, onde $66 \%$ dos usuários consideram que nem sempre o aplicativo fornece um uso eficaz e compreensível.

Novamente acredita-se que o padrão de formatação das funções em aplicativos do sistema IOS pode ter interferido neste resultado.

\subsection{Questões sobre o uso}

O predomínio da opinião positiva acerca da identificação do campo de busca foi atribuída ao layout do aplicativo, que através do alto contraste, design limpo e ênfase ao campo de busca (localizado no centro da página inicial) dá ênfase a esta função, considerada a principal do Zoom. Também se acredita que é devido a esse destaque que os usuários entrevistados só fizeram busca através da digitação do nome do produto, ao invés de usar outros meios (leitura de códigos de barras e uso do menu por grupos).

De acordo com a pesquisa, $66 \%$ dos usuários do Android considerou fácil ou muito fácil selecionar o produto, assim como salvar o produto, enquanto que $85 \%$ dos usuários do IOS tiveram a mesma opinião sobre encontrar o produto, porém essa porcentagem cai para $71 \%$ quanto à facilidade para salvar o produto.

A criação do alerta foi um ponto com certa representatividade de opiniões que relatam dificuldade, assim como na tarefa de exclusão do produto da lista de produtos salvos. Alguns usuários relataram que a dificuldade estava em entender que o sino era um alerta, e afirmaram que os símbolos de sino e coração estavam muito claros e com pouco destaque (queixa retratada principalmente por usuários do sistema IOS). 


\subsection{Interface}

No campo da compreensão das funções percebe-se uma distinção entre as opiniões dos usuários das diferentes plataformas. Usuários do Android foram neutros com relação à sua facilidade, enquanto usuários do IOS em sua maioria consideraram muito fácil. Este dado leva à conclusão de que o aplicativo segue uma estrutura parecida nas duas plataformas, porém semelhante à estrutura de outros aplicativos do sistema IOS, o que pode levar a certa dificuldade para outros usuários.

Opiniões muito semelhantes são apresentadas com relação ao tamanho dos ícones, pois em geral todos os usuários consideraram bom ou muito bom, assim como o contraste. Neste último, imaginava-se que as cores utilizadas no sistema IOS (cinza sobre branco, enquanto que na outra plataforma as cores são roxo escuro sobre branco) fosse trazer um resultado diferente, indicando insatisfação dos usuários, porém o cenário foi semelhante.

Finalizando a análise da opinião do usuário, observou-se uma predominante satisfação com relação ao texto exposto e à utilização das funções do menu, e alguns usuários (de ambas plataformas) afirmaram ter sentido dificuldade para relacionar os símbolos com as ações. Acredita-se que a falta de destaque para esses itens no menu, ou a ausência de caminhos alternativos para algumas tarefas tenha levado a esses usuários a sentir dificuldades com o uso do aplicativo.

\section{RECOMENDAÇÕES DE USABILIDADE}

Tomando como base o cruzamento de duas avaliações (heurística e a opinião do usuário), além da análise comparativa entre concorrentes e entre as duas plataformas, a equipe acredita ter fundamentos sólidos para propor algumas recomendações de usabilidade para o aplicativo.

\subsection{Quanto ao Layout}

- O destaque dado ao campo de busca mostrou-se bastante eficiente, então recomenda-se dar maior destaque aos diferentes meios de busca, como o uso do código de barras. A Equipe observou que, quando notado, o ícone tem sua função compreendida, então recomenda-se aumentar o tamanho do ícone, assim como aumentar o seu contraste com o fundo branco na plataforma IOS. Esta função é um dos pontos fortes do aplicativo e poderia aumentar sua popularidade, além de ser um atalho para usuários experientes;

- Devido à dificuldade encontrada por alguns usuários em identificar a função de "Salvar produto", recomenda-se maior destaque ao ícone do coração, através de aumento de tamanho e contraste com o fundo branco. A posição do ícone já é adequada, porém a falta de destaque leva o usuário a não considerá-lo como uma função importante;

- Outro diferencial do aplicativo é a criação de alertas de preço enquanto mostra ao usuário o comportamento do preço do produto ao longo do ano, porém a função encontra-se com pouco destaque, o que leva os usuários a não considerarem o ícone como uma função importante. Recomenda-se o aumento do contraste com o fundo branco, assim como o aumento das dimensões do símbolo do "sino";

- Outros meios de busca, como a utilização dos menus em grupos, não possuem o devido destaque na plataforma IOS. Recomenda-se que o aplicativo nesta plataforma siga o padrão da plataforma Android, que tem maior contraste e destaque para esses menus. São uma alternativa interessante que é pouco explorada pelos usuários;

- A função de excluir o produto da lista de favoritos tem funcionamento mais facilmente 
compreendido na plataforma IOS. Recomenda-se o uso deste padrão na plataforma Android, que trouxe certa confusão para alguns usuários.

\subsection{Quanto à Consistência}

- Recomenda-se que o aplicativo tenha comportamento similar em ambas plataformas, pois cada uma tem pontos negativos cujas soluções estão sendo aplicadas na outra. Ex: contraste bom dos menus no android, exclusão do produto da lista de favoritos do IOS.

\section{CONSIDERAÇÕES FINAIS}

Atendendo às demandas de um mundo competitivo e em constante transformação, o aplicativo zoom está sempre em desenvolvimento. Durante nossos estudos houve uma atualização do sistema disponível, onde já pudemos observar algumas melhorias. É importante notar a preocupação dos desenvolvedores do sistema para questões de usabilidade, o que garante a satisfação dos usuários.

Este estudo mostra que o aplicativo possui boa interface e atende à maioria dos princípios de usabilidade, como coerência, controle do usuário, consistência, estética e design minimalista, ajuda e documentação. O que pode ser melhorado diz respeito ao princípio de compatibilidade, pois os usuários não conseguiram identificar o ícone que representa 0 escaneamento do código de barras como tal.

Além disso, é recomendável que, na versão para Android haja uma reestruturação na exclusão do produto salvo, o que pode ser facilmente corrigido, visto que, na versão para IOS a função não apresenta essa inconsistência. Também é sugerida a implementação de uma função que permita ao usuário moldar a ordem dos produtos salvos de acordo com o critério escolhido por ele, por exemplo: preço, tipo de produto ou qualquer outro. Isto melhoraria a flexibilidade e eficiência de uso do sistema.

Para melhorar a liberdade e controle do usuário sugerimos a implementação de uma função na qual o usuário possa avaliar os produtos pelo aplicativo, pois na versão atual o usuário só pode avaliar o produto através do site.

A preocupação com a usabilidade dos produtos e sistemas se faz cada dia mais necessária, devido à complexidade do mundo moderno e suas tecnologias e à variedade de usuários que os produtos atingem. Um design acessível à qualquer tipo de usuário é fruto da participação desse agente no processo de desenvolvimento do produto. A avaliação heurística se mostrou muito importante para facilitar a análise de usabilidade do produto, e aliada à avaliação com os usuários, através da aplicação dos questionários, se mostrou muito eficiente, visto que o usuário é o foco no desenvolvimento de qualquer produto, seja ele físico ou virtual.

\section{REFERÊNCIAS BIBLIOGRÁFICAS}

ASSOCIAÇÃO BRASILEIRA DE NORMAS TÉCNICAS. NBR 9241-11: requisitos ergonômicos para trabalho de escritórios com computadores: parte 11 - orientações sobre usabilidade. Rio de Janeiro, p.3, 2002.

AHRAM, Tareq . Usability Analysis of Sony Entertainment's Star Wars Galaxies. Notas de aula, 2014. 
CHIN, John, DIEHL, Virginia, NORMAN, Kent. Development of an Instrument Measuring User Satisfaction of the Human-Computer Interface. ACM CHI'88 Proceedings, 213-218, 1988.

CYBIS, Walter; BETIOL, Adriana Holtz; FAUST, Richard. Ergonomia e usabilidade: conhecimentos, métodos e aplicações. 1ed. São Paulo: Novatec, 2007.

IIDA, Itiro. Ergonomia: projeto e produção . 2. ed. rev. e ampl. São Paulo: Edgard Blucher, 2005.

JORDAN, Patrick W. An Introduction to Usability. Taylor \& Francis Ltd, 1998.

LEVENTHAL, Laura M.; BARNES, Julie A. Usability Engineering: process, products and examples. Pearson, 2008.

NIELSEN, Jakob. Usability Engineering. San Diego: Morgan Kaufmann, 1993.

STANTON, Neville; BARBER, Christopher. Error by design: methods for predicting device usability. Design Studies. Vol. 23, N ${ }^{\circ}$ 4. London, Elsevier Science Ltd, July - 2002. p. $363-384$, 2002. 